\title{
Development and Evaluation of Anti-coyote Electric Fencing
}

\section{N. L. GATES, J. E. RICH, D. D. GODTEL, AND C. V. HULET}

Highlight: An electric fence with alternating ground and charged wires was tested for anti-coyote properties. Under the conditions tested, the fence was coyote proof. The fence may evolve as an effective, nonlethal method of preventing coyote depredation of domestic livestock.

Fencing as a means of excluding canid predators from domestic livestock has received continued interest for many years. Modern use of barrier fencing as a nonlethal method for controlling canid depredation on domestic livestock began in Australia about 1900. By 1908, $9,012 \mathrm{~km}$ of dingo (Canis dingo) fencing had been built in South Australia (McKnight 1969). In the United States, "coyote proof" fencing for protecting sheep was described in 1911 (Jardine). Although a "coyote proof" fence conceivably could have been designed, the fence configuration developed by Jardine (1911) certainly was not "coyote proof." Since that time, various researchers have tested a multitude of fence designs to deter coyotes (Canis latrans).

Because of the relatively low cost involved, electric fencing has been a concept of particular interest. Unfortunately, the results of research on electric fencing have been discouraging. Shelton (1973) concluded that poor grounding of the coyote and the insulating effect of vegetation and fur on the animal's body reduced the electric shock to the extent that the electric fences tested were ineffective in deterring coyotes. Thompson (1976) evaluated 18 electric fence configurations and observed that in 466 tests, coyotes responded to the electric shock only 13 times. Consequently, he concluded that electric fences were generally ineffective for controlling coyotes. Occasional undocumented reports of effective use of electric fencing for warding off coyotes and dogs (Canis familiaris) are heard of. These reports have kept alive interest concerning eventual development of practical, effective electric anti-predator fencing. The obvious attributes of such a fence would be (1) relatively low cost, (2) environmental acceptability, and (3) immediate availability.

The purpose of this study was to develop and evaluate practical electric fencing that would effectively protect sheep from coyotes.

At the time of the research, all authors were with the U.S. Sheep Experiment Station, U.S. Department of Agriculture, Agricultural Research Service, Dubois, Idaho 83423, in cooperation with the University of Idaho, Moscow. D. D. Godtel is now with the U.S. Forest Service, U.S. Dep. Agr., Eureka, Montana.

The authors wish to acknowledge the technical assistance of Robert L. Piesse, Melbourne, Australia, and Mark Armbruster, Moscow, Idaho.

Manuscript received August 10, 1977.

\section{Materials and Methods}

Trials were conducted within a 64-ha, coyote-proof test pasture. A pair of captive wild coyotes with radiotransmitter collars were contained in the pasture. Two sheep enclosures were constructed within the 64-ha pasture. Each sheep enclosure was about $8,000 \mathrm{~m}^{2}$. One enclosure was constructed to approximate conventional sheep fence $(81.3-\mathrm{cm}$ woven wire with two strands of barbed wire spaced 15 $\mathrm{cm}$ apart above the woven wire). The other sheep enclosure was an electric fence consisting of 12 wires alternating ground to hot beginning with the bottom wire (Fig. 1). An additional hot wire (trip wire) was placed $20 \mathrm{~cm}$ from the fence around the outside perimeter and $15 \mathrm{~cm}$ from the ground (Fig. 1). All ground wires were connected to four $2.5 \mathrm{~cm}$ steel pipes driven about $1.5 \mathrm{~m}$ into the ground (Fig. 3). All energized wires were connected to a 12 -volt charger ${ }^{1,2}$ (Fig. 4). Fiber glass fence posts and battens were used between wooden corner and brace posts. Wire was $12.5 \mathrm{ga}, 1,000 \mathrm{psi}$, and was strained to $181-\mathrm{kg}$ tension. A nonenergized gate was constructed from $2.5 \times 5 \mathrm{~cm}$ welded fabric and alluminum tubing. A wood sill was buried under the gate (Fig. 5). End post wire strainers were used (Fig. 6). Corner post detail is shown (Fig. 7).

Each trial lasted for 2 weeks. The trial was replicated twice. A different pair of coyotes was used in each trial. Eight lambs were placed within each of the two sheep enclosures at the beginning of each trial. Lambs were observed daily. All dead lambs were necropsied to determine cause of death.

\section{Results and Discussion}

All lambs confined in conventional woven and barbed wire enclosures were killed by coyotes in all trials (Table 1). No lambs confined within the electric enclosures were killed by coyotes in any of the trials.

Results from this investigation clearly show that properly designed electric fencing can effectively protect sheep from coyotes and thus contradict conclusions from previous reports. Lack of adequate grounding was overcome by alternating ground and charged wires and by connecting all ground wires to grounding posts. Digging under the fence by the coyotes was prevented by the incorporation of the charged

\section{${ }^{1}$ Model E12, Gallagher Electronics, Ltd., Frankton, Hamilton, New Zealand}

- Mention of a trade name, proprietary product, or specific equipment does not constitute a guarantee or warranty by the U.S. Dep. Agr. and does not imply its approval to the exclusion of other products that may be suitable. 


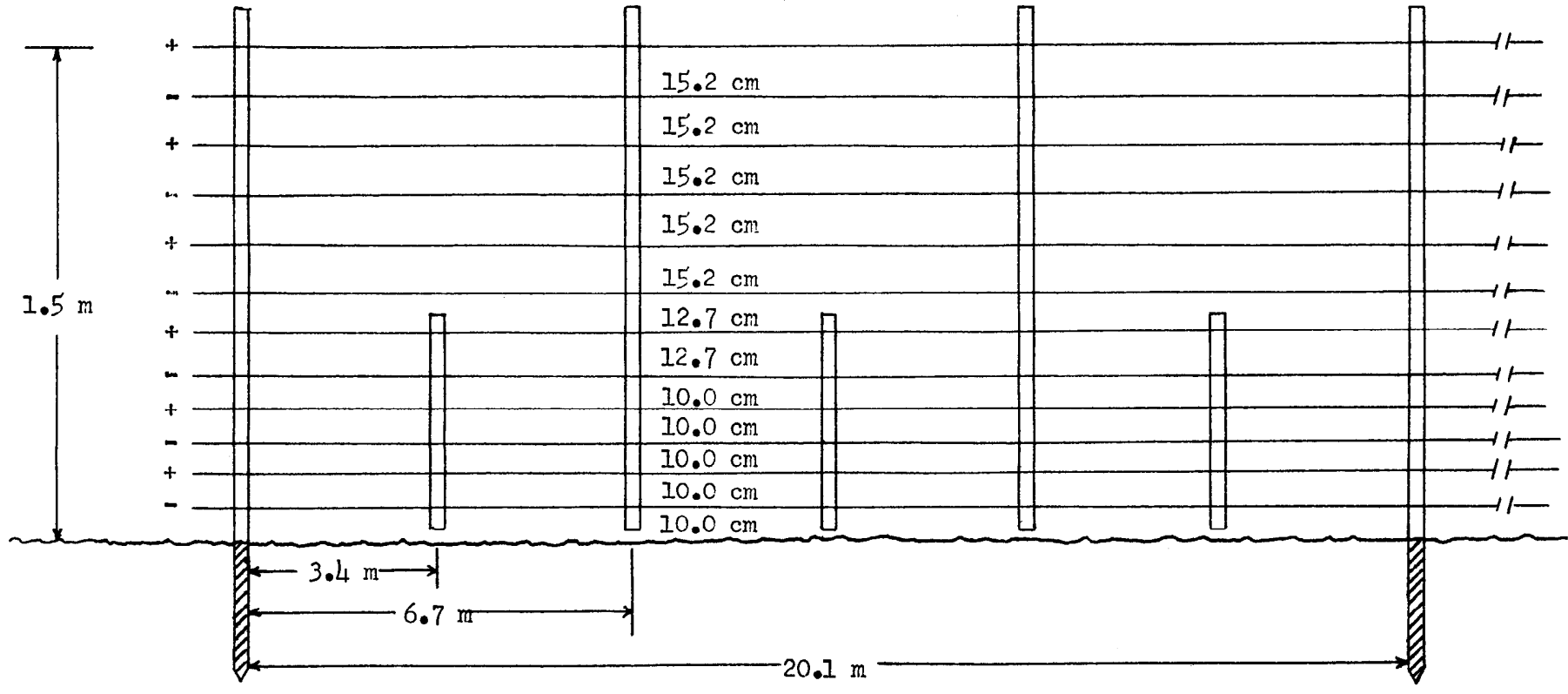

Fig. 1. Electric fence configuration.

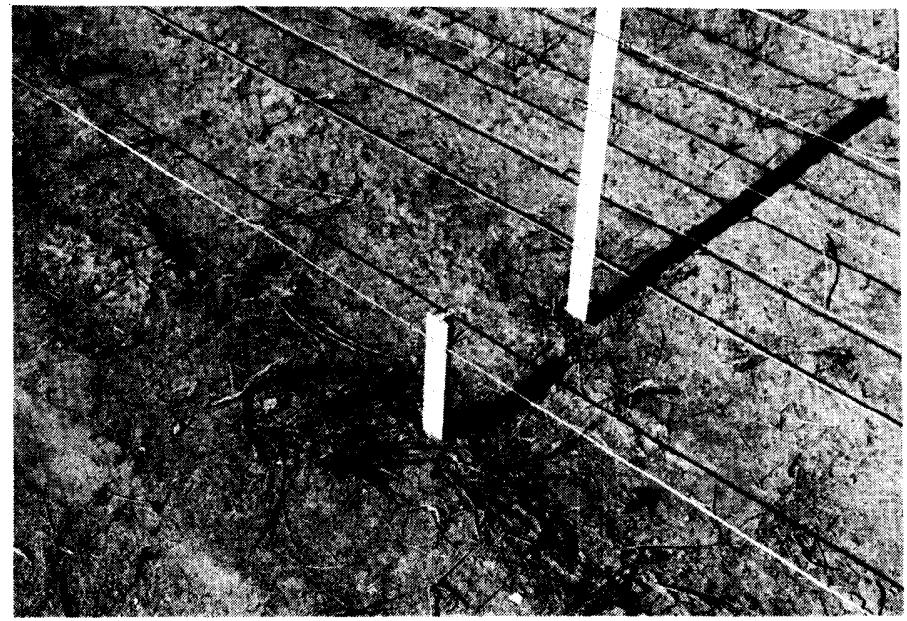

Fig. 2. Charged trip wire around perimeter of fence.

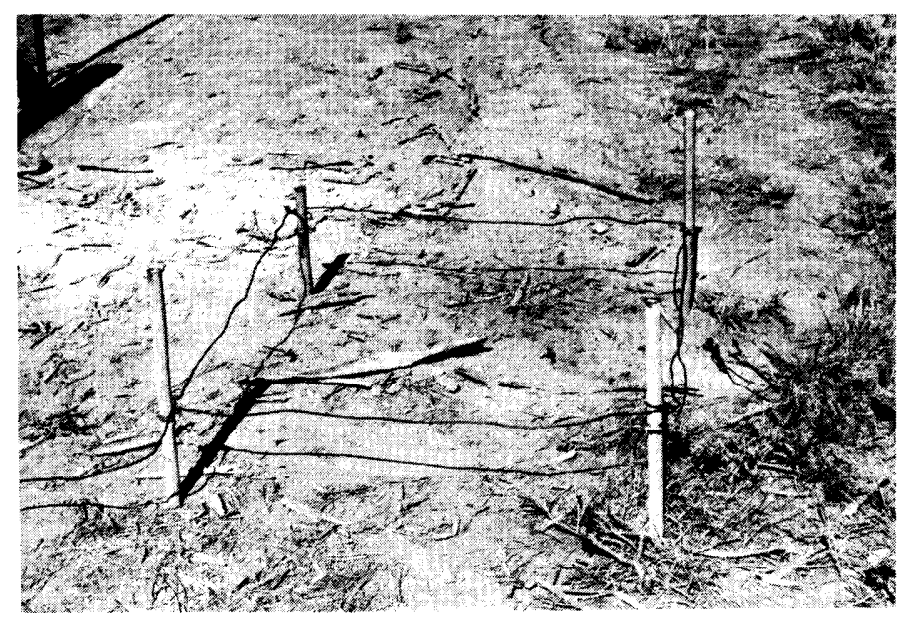

Fig. 3. Grounding posts.

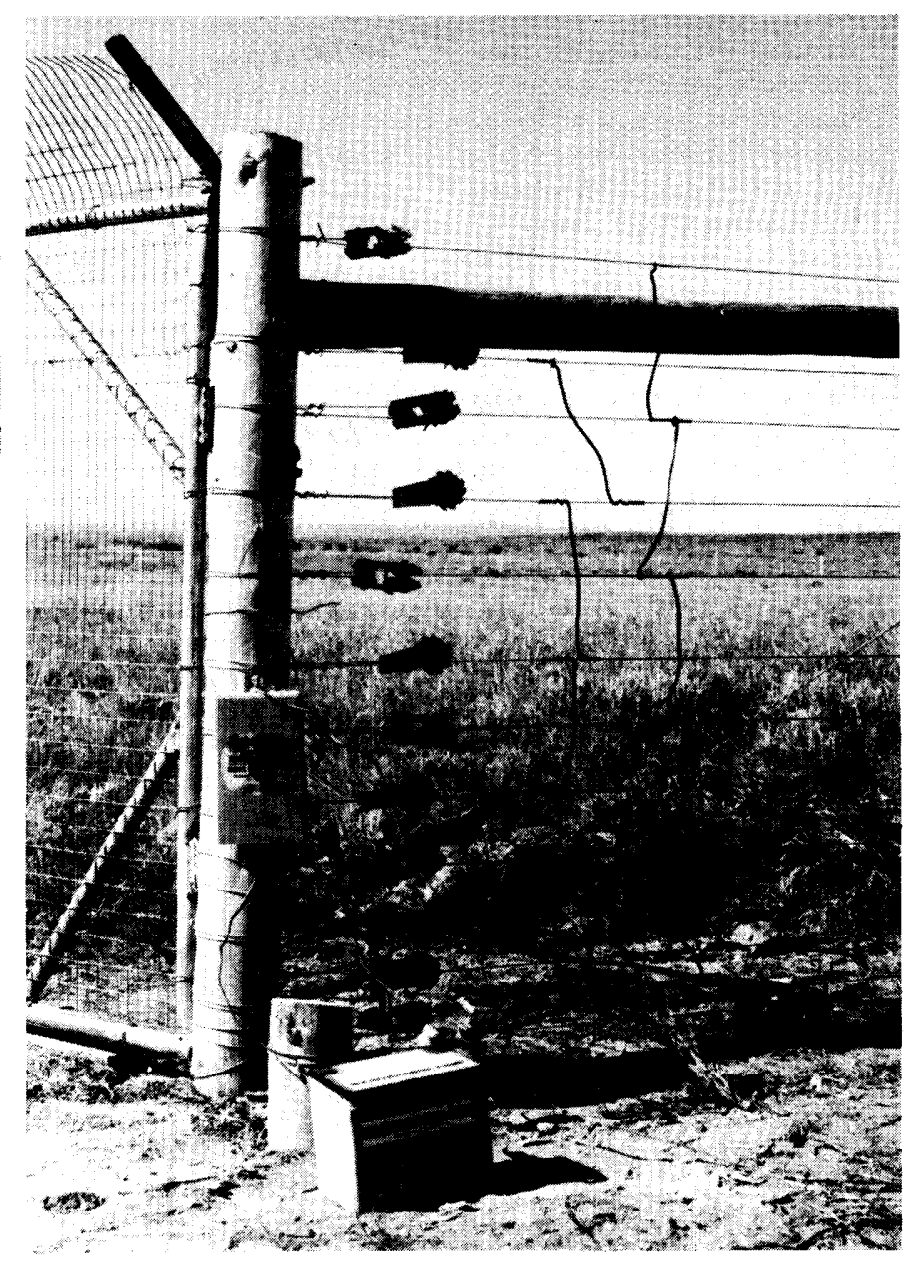

Fig. 4. Battery charged energizer attached to gate post. 

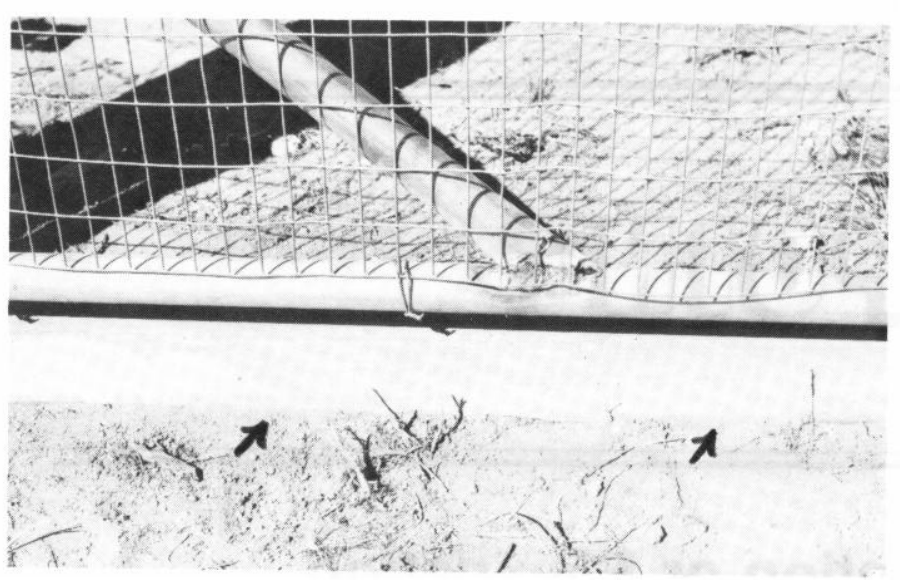

Fig. 5. Sill under gate to prevent dig under.

Table 1. Kill frequency (number killed/day) of lambs confined within conventional sheep enclosure.

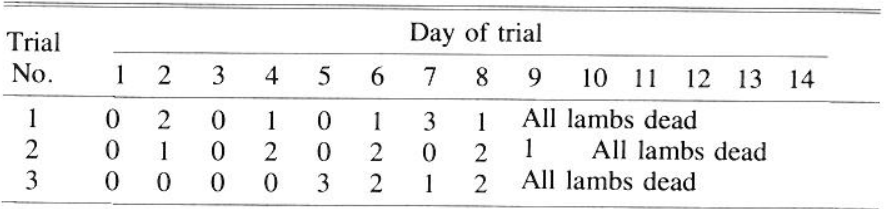

trip wire. Furthermore, the high pulse current capacity of the energizer used in this investigation resulted in a relatively high line voltage $(3,000-5,000 \mathrm{~V})$ and thus overcame voltage drainage factors such as fence contact with brush. The reader should not conclude that the configuration used in this study could not be modified, perhaps by use of fewer wires, different spacings between wires, or different sources of power. The post and stay spacings shown (Fig. 1) would probably be subject to modification, depending upon the slope of the terrain.

Additional advantages of the fence described in this report would be economic feasibility and environmental acceptability. The estimated cost of materials used in the fence tested is $\$ 1,000$ per $\mathrm{km}$; the cost of materials used in conventional woven and barbed wire fences is about $\$ 1,500$ per $\mathrm{km}$. With regard to environmental acceptability, the electric fence could not be used where it would interfere with antelope movement. Birds of prey (raptors) could be kept off the fence by metal cones attached to the tops of wooden posts. Adult deer should have

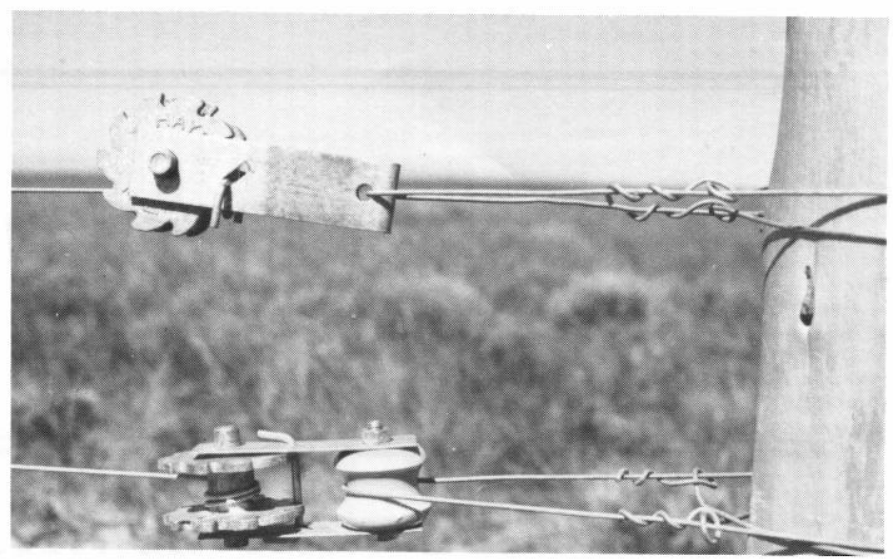

Fig. 6. Insulated (bottom) and noninsulated post wire strainers for attaching charged and ground wires, respectively.

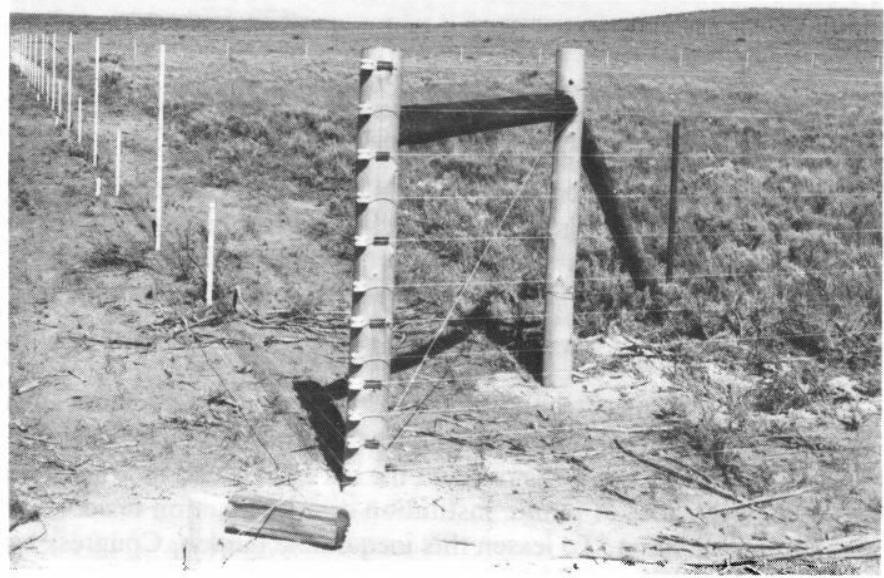

Fig. 7. Detail of corner post.

little difficulty in jumping the fence although fawns probably could not get through. Because of the foregoing considerations, obviously, the electric fence may evolve as an effective, nonlethal method for preventing coyote depredation on sheep and may have widespread, but not universal, application.

\section{回回}

